\title{
COMO TORNAR-SE ADULTO: processos de transição na modernidade avançada
}

\section{Maria das Dores Guerreiro e Pedro Abrantes}

\section{Introdução}

A par das mudanças que a vários níveis ocorrem na sociedade contemporânea, também os processos de entrada na vida adulta sofrem importantes transformações. À medida que o acesso à informação e a todo um conjunto vasto de recursos se disseminam em escala global e estão disponíveis às populações, permeando e moldando os seus cotidianos, encontram-se cada vez mais pontos de convergência entre as formas de ser jovem e viver a transição para o estatuto de adulto em diferentes sociedades. Percursos escolares mais prolongados, inserções profissionais mais tardias e instáveis, homologias nos papéis de gênero são, entre outros, fatores transversais que redefinem os

Artigo recebido em outubro/2004

Aprovado em abril/2005 modos de atingir a condição adulta por parte das gerações mais novas.

Ao longo das últimas quatro décadas, a acelerada escolarização, urbanização e terceirização da população portuguesa, juntamente com alterações profundas em todas as esferas da vida social, aproximaram a sociedade portuguesa dos padrões europeus, embora subsistam fragilidades e atrasos estruturais que têm levado, em trabalhos de síntese, a considerar-se que Portugal se caracteriza hoje por uma "modernização inacabada" (Machado e Costa, 1998) e uma posição "semi-periférica" no sistema global contemporâneo (Santos, 2001). Do mesmo modo, nas transições juvenis para a vida adulta, apesar da proximidade com as vividas noutros países europeus encontram-se-lhes também traços particulares, reflexo das condições estruturais da sociedade portuguesa.

A análise que neste artigo se apresenta sobre as formas como as jovens gerações se tornam adul- 
tas baseia-se nas principais conclusões de um projeto de investigação levado a cabo em $1997^{1}$ e que incluiu, na sua primeira fase, além de uma pesquisa teórica e estatística, a realização de entrevistas de grupo e entrevistas individuais com moças e rapazes, no intuito de reconstituir condições e histórias de vida, práticas e representações, projetos e expectativas quanto ao futuro. A amostra restringiu-se à região de Lisboa e baseou-se na definição de clusters de jovens em contextos diferenciados e em situações de vida distintas. A transição para a condição de adulto foi equacionada em moldes multidimensionais; neste artigo, a análise centra-se em quatro dimensões fundamentais: educação, trabalho, família e gênero. Assim, respeita-se esta segmentação. Na seção final ensaia-se uma tipologia de modos de transição para a vida adulta, como forma de captar as modalidades complexas por meio das quais se articulam e se entrelaçam essas várias dimensões nas trajetórias dos jovens.

\section{Assimetrias nos percursos escolares}

Nas sociedades do conhecimento é atribuída grande importância aos saberes e às qualificações formais, adquiridos mediante o sistema de ensino. Cresce e diversifica-se o leque de ocupações profissionais e técnicas de elevada qualificação a que só acedem os detentores de diplomas de nível superior, designados por alguns autores de "analistas simbólicos" (Reich, 1993). Todo este conjunto de empregos técnicos e científicos, bem recompensados e prestigiados, está associado a aspirações e investimentos crescentes na educação.

$\mathrm{O}$ alargamento das oportunidades educativas fez-se sentir em Portugal, de forma acentuada, sobretudo após a revolução de abril de 1974. A universidade deixou de ser um privilégio das elites, tornando-se, para muitos jovens, a porta de acesso às "novas classes médias". Se nessa altura menos de $5 \%$ da população dos 25 a 29 anos possuía um diploma de nível superior, em 2001 já o detêm perto de $27 \%$ de jovens dessa faixa etária (INE, 2001).

Esta transformação foi visível nos trajetos, nas representações e nas expectativas de uma grande parte dos jovens entrevistados, refletindo uma clara mudança social. Como outros estudos já vinham notando (Costa et al., 1990), para os jovens que lhe conseguem aceder, o ensino superior representa uma transformação significativa das redes de sociabilidade e dos estilos de vida e, sobretudo, uma enorme abertura de perspectivas em face do futuro. Tal como nos restantes países onde decorreu a pesquisa, em Portugal emerge um grupo de jovens altamente envolvidos nos cotidianos universitários e com grande expectativa em relação ao futuro profissional (Lewis et al., 1999). Querem aproveitar as oportunidades que os pais não tiveram e escolher uma profissão em que se sintam realizados. Seus trajetos de vida, sua auto-realização e suas representações são bastante tributários dos percursos e das oportunidades de formação. Gostam do estatuto de estudantes e, muitos deles, continuam trajetos de formação mesmo depois de terminada a licenciatura. A maioria revela vontade de ter formação no estrangeiro, pois deseja viajar, aprender, conhecer, contatar com outras culturas, confirmando uma relação já estudada entre a formação avançada e a condição cosmopolita (Peixoto, 1999). Estes jovens dependem, em grande medida, do suporte econômico dos pais, que investem significativamente num projeto de escolarização e mobilidade social de seus filhos.

Essa massificação do ensino superior alterou significativamente os trajetos e os projetos de uma faixa já considerável da juventude portuguesa, transformando decisivamente o processo de entrada na vida adulta, à imagem daquilo que já acontece desde os anos de 1960 nos países da Europa Central. Alguns autores têm assinalado a criação de múltiplas opções, situações e oportunidades para os jovens, conduzindo à desestandardização, à não-linearidade e à individualização das biografias (Cavalli, 1995; Galland, 1995; Pais, 2001). Ainda assim, a presente pesquisa mostra que o prolongamento dos projetos acadêmicos é, em geral, inconciliável com a idéia de, a curto prazo, obter um emprego seguro ou constituir família, confirmado estudos inquéritos recentes que apontam no mesmo sentido (Mauritti, 2002). É verdade que a 
expansão recente dos trabalhos temporários ou a tempo parcial veio criar novas condições e situações híbridas e transitórias (Mortimer et al., 1999), mas em Portugal apenas $7 \%$ dos jovens trabalham e estudam simultaneamente, sendo que a média na União Européia é de 16\%, e em países como a Holanda ou a Dinamarca atinge $44 \%$ e 37\%, respectivamente (Eurostat, 2003). Para a grande maioria dos estudantes universitários portugueses, o ensino superior constitui, de fato, um adiamento do processo de transição para a vida adulta, a par de um aumento das expectativas em face do futuro.

Esse aumento na faixa de jovens universitários não nos deve fazer esquecer que muitos outros continuam a ingressar cedo no mercado de trabalho, parte deles sem terminar sequer o ensino obrigatório. Estudos recentes mostram que $40 \%$ dos jovens entram ainda no mercado de trabalho no escalão etário dos 15-17 anos, sem possuir quaisquer qualificações (Alves, 1998) e que a população entre 17 e 24 anos tem o trabalho como principal meio de subsistência (Garcia et al., 2000; INE, 2001).

A generalização da escolaridade básica não significa a generalização das experiências escolares bem-sucedidas. Confirmando uma tendência identificada por Benavente et al. (1994), a pesquisa empírica revelou como os insucessos e as reprovações, o desinteresse pelas "matérias", os círculos de amigos e a vontade de trabalhar, ganhar dinheiro ou conquistar autonomia tendem a convergir e a acumular-se em trajetórias de exclusão da escola. Uma parte substancial dos jovens não concluiu a escolaridade básica ou fê-lo já em idade tardia e em clara ruptura com o sistema educativo. Nas narrativas, o abandono escolar surge quase como uma "fatalidade", ditada por acontecimentos marcantes que obrigaram ao afastamento da escola. Uma análise mais aprofundada permite compreender que esses jovens não só possuíam anteriormente experiências escolares pautadas pelo desinteresse e pelo insucesso, como também são originários de classes desfavorecidas e sem qualificações superiores, isto é, são filhos de operários ou de empregados executantes. ${ }^{2}$
Eu ia jogar à bola e esquecia a escola. Mas agora vejo a vida de maneira diferente. Sem educação não se consegue um emprego melhor nem melhores condições de vida (Entrevista de grupo: jovens operários do sexo masculino)

Larguei a escola porque os meus pais não tinham mais... eu queria avançar, queria ir para qualquer lugar e não tinha dinheiro, então espera aí, acabou a escola, aquilo que sei, sei, aquilo que não sei, que se lixe. Mas estou bem arrependido. Comecei a trabalhar e foi até hoje (Entrevista de grupo: jovens operários do sexo masculino)

Muitos dos jovens que abandonaram prematuramente a escola sentem, poucos anos volvidos, a necessidade de mais qualificações e de novas competências para enfrentar um mercado de trabalho em acelerada transformação e que, cada vez mais, parece preferir as qualificações escolares, desvalorizando os saberes práticos. Dessa forma, o ensino noturno, em todos os seus graus, tem constituído uma opção bastante popular entre os jovens portugueses que pretendem começar a trabalhar mas, simultaneamente, aumentar as suas qualificações.

Note-se que os modestos rendimentos dos portugueses no geral, em comparação com o restante da Europa, implica que o reatar dos projetos escolares se faz, em grande medida, sem questionar o prosseguimento da vida profissional. Diante da insuficiência de apoios estatais e de um tecido empresarial dominado pelas pequenas e médias empresas, situadas em setores pouco qualificados e nem sempre abertas à aposta na formação (Freire, 1998; Guerreiro et al., 2000), a grande maioria dos jovens que regressa aos estudos, fá-lo por sua conta e em concomitância com o emprego. Procuram manter uma vida dupla: a de profissionais e estudantes, tendo embora de enfrentar diversos obstáculos, nem sempre fáceis de superar:

Eu trabalho em hotelaria [...]. É a necessidade, neste momento, como estou a tirar o curso, há certos ramos em que é difícil um part-time... (Entrevista de grupo: estudantes do ensino profissional do sexo feminino). 
[...] Trabalhadores-estudantes no nosso país, as condições que têm são mínimas... O meu irmão não completou o $12^{\circ}$ ano porque trabalhava por turnos e a escola não tinha um regime flexível (Entrevista de grupo: jovens empregadas administrativas).

Esta "escolha crítica" (mercado de trabalho versus estudos superiores) é muito condicionada por variáveis sociais - classe, etnia, sexo, local de residência - bem como condições e experiências proporcionadas pelos próprios sistemas de ensino e de emprego, que tendem a delimitar oportunidades e vocações no sentido da reprodução das estruturas e das desigualdades sociais (Bourdieu, 1984). A juzante, essa opção abre dois universos de transição diferenciados (Banks et al., 1992), até porque a minoria de jovens com níveis de formação intermediária (secundário) enfrenta grandes dificuldades de inserção profissional, sendo hoje o grupo com maior taxa de desemprego (Pais, 2001).

Entre as duas vias clássicas, tem-se assistido, em Portugal, à expansão da formação profissional como uma terceira via, depois de quase ter desaparecido após 1974. Reproduzindo uma tendência européia das últimas décadas, os últimos anos têm sido marcados por uma clara aposta no desenvolvimento do sistema de formação profissional, em grande parte financiado pela União Européia (UE). Hoje, "aproximadamente 1 em cada 4 jovens que prosseguem os estudos após o $9^{\circ}$ ano freqüenta um ensino tecnológico e profissional" (Grácio, 2000, p. 136). Esta expansão vem ao encontro de dois fluxos cruzados: a) as crescentes exigências da nova economia, cuja competitividade e inovação dependem de capital humano com novas competências e conhecimentos (Castells, 1998); b) a contração do mercado de trabalho, que faz com que os cursos sejam uma ocupação e uma nova esperança para jovens em situação de desemprego iminente ou efetivo (Neves, 2000).

\section{$O$ ingresso no mundo do trabalho}

Independentemente da tônica de diversas análises, seja anunciando o seu colapso (Jenkins e
Sherman, 1979; Rifkin, 1995) ou enfatizando a sua importância como elemento fundamental de estruturação das sociedades e das identidades contemporâneas (Beck, 1992, 2000), não há dúvida de que mudanças significativas têm reconfigurado a organização do trabalho e as formas de emprego (Handy, 1986). As jovens gerações são protagonistas por excelência dessas novas dinâmicas, tanto na esfera das oportunidades como dos riscos que representam. As tendências registradas nas últimas décadas na esfera do trabalho implicaram mudanças significativas nos contextos, nas experiências e nas oportunidades laborais dos jovens, gerando novos perfis, identidades, poderes e culturas profissionais (Castells, 1996).

As qualificações escolares, científicas e técnicas, proporcionam condições e oportunidades acrescidas nos setores qualificados em expansão, até devido aos baixos níveis de qualificação registrados nas gerações anteriores. Assim, um contingente significativo de jovens caracteriza-se por trajetos escolares longos, e uma entrada tardia e favorecida no mercado de trabalho. Desde cedo, ocupam lugares de decisão nas organizações (Freire, 1998; Cordeiro, 2002) e auferem salários relativamente altos para a sociedade portuguesa, mesmo em situação contratual precária. Possuem, cada vez mais, uma "condição cosmopolita" (Peixoto, 1999), circulando livremente na rede global extraindo daí enormes capitais econômicos, relacionais e de status (Castells, 1996). Integram um enclave de trabalhadores privilegiados, seduzidos pelas múltiplas possibilidades da pós-modernidade, quantas vezes indiferentes à situação da maioria (Clegg, 1998).

Apesar da situação de privilégio relativo, muitos desses jovens são obrigados a seguir horários de trabalho bastante prolongados (10-12 horas diárias), por vezes ainda complementados por ações de formação. Fazem-no por necessidade de sobrevivência num contexto profissional muito exigente e competitivo, mas também por expectativas de promoção a curto prazo. Nesses casos, a constituição de família ou as atividades de lazer são, em geral, remetidas para um cenário futuro, 
após a conquista de estatuto e estabilidade profissionais. Alguns depoimentos são elucidativos:

Eu tenho muita pena que não seja compatível o fato de uma mulher ter um filho e poder seguir a sua carreira profissional [...] às vezes não são propriamente compatíveis numa determinada altura... (Entrevista de grupo: economista, sexo feminino).

[...] [o patrão] dá aquele ar de patrão porreiro, mas o que acontece é que ele diz para a gente entrar a uma hora qualquer, mas não diz a hora de saída! É raro o dia em que trabalho 8 horas. Trabalho sempre mais [...]. Em termos profissionais, [o principal objetivo] é ter um contrato e ter um horário que me permita ser mãe e não ter posto só um filho no mundo (Entrevista individual: bióloga).

Esta casta de jovens privilegiados coexiste com uma maioria, alguns com qualificações superiores ou intermediárias, que "caem nas malhas do temporário" (expressão de um entrevistado). Entram num círculo cada vez mais longo de trabalhos rotineiros e temporários, com vínculos precários, rendimentos reduzidos, em muitos casos não muito além do salário mínimo e sem benefícios sociais, passando por experiências de desemprego (Pais, 2001), enquanto sonham com um emprego estável e valorizado e adiam indefinidamente a entrada na vida adulta.

Note-se, porém, que apesar das análises mais pessimistas (Sennett, 1998; Bauman, 1999) prevalece ainda um sistema estável e padronizado de emprego. Mas coexiste hoje com uma panóplia de formas flexíveis de trabalho (Beck, 2000), em franca expansão sobretudo entre as camadas etárias mais novas, e com reduzidos direitos e regalias sociais (Lewis et al., 2002b). A flexibilidade, teorizada por alguns como traço característico da força de trabalho jovem e a precarização dos vínculos laborais (Supiot, 2001), reforçada pelo enfraquecimento dos sindicatos e da participação dos trabalhadores nas decisões tomadas pelas organizações de trabalho, surgem como uma tendência estruturante das sociedades contemporâneas, obrigando os trabalhadores a lidarem constantemente com o risco e a insegurança
(Castells, 1996; Beck, 2000). Um pouco por todo o lado, os jovens comentam, sem grande nostalgia, que "já não há empregos para toda a vida". O que parece específico do caso português é que a precarização dos vínculos laborais se sobrepõe a um quadro legal sistematicamente transgredido e a um cenário laboral de condições tradicionalmente precárias. O trabalho informal, fortemente enraizado em Portugal, tende a adaptar-se e a subsistir na nova era, representando o "grau zero" dos direitos sociais e laborais. As datas de pagamentos, bem como os montantes auferidos são freqüentemente problemáticos e é também freqüente a imposição de horários prolongados, sem direito a vencimentos extras. A este propósito, note-se que a maioria dos jovens entrevistados nesta pesquisa revelou, neste momento, trabalhar sem contrato, situação que lhes foi apresentada como inevitável ou até vantajosa a curto prazo, visto não descontarem para impostos e segurança social.

As taxas de desemprego, que em Portugal têm sido "oficialmente" baixas, aumentaram nos últimos anos, contrariando tendências de recuperação registadas na União Européia e constituindo-se como um dos mais sérios desafios à coesão e à integração na sociedade portuguesa. Contabilizada no final de 2004 em 7,1\%, para o total da população, a taxa de desemprego mais do que duplica $(15,8 \%)$ para a faixa etária dos 15 aos 24 anos (dados do Instituto Nacional de Estatística). Cerca de um terço dos desempregados tem menos de 30 anos. Uma fração muito significativa de jovens transita entre "ocupações flutuantes", situando-se numa "zona cinzenta" ou de "integração periférica", de difícil análise sociológica, mesmo por intermédio de metodologias qualitativas, a inserção profissional efetiva e o desemprego tradicional.

A construção de biografias e identidades enfrenta, pois, uma descontinuidade entre a insegurança crescente no mercado de trabalho e os valores dominantes de segurança, planejamento e bem-estar na esfera pessoal-familiar. A seguinte resposta é um exemplo da dificuldade em gerir essa contradição: 
Para já, para as pessoas que estão a acabar os cursos [o principal objetivo] é acabá-los a bom termo... e depois é começar... essa questão é muito difícil! A grande preocupação é essa: encontrar um trabalho... tirar um curso e depois não ter um trabalho onde o usar... acho que hoje em dia é uma grande confusão. [O principal objetivo] é entrar num trabalho, arranjar uma coisa com mais ou menos estabilidade - não sei se será possível, pelo menos a princípio não é possível, como está hoje a sociedade... - e acho que é isso: tentar encontrar um emprego que dê algumas garantias, que permita que a pessoa depois comece a construir a sua vida... (Entrevista de grupo: jovens desempregados do sexo masculino).

Os trajetos lineares da escola para o trabalho tendem a converter-se em "trajetórias yo-yo", alternando períodos de desemprego, emprego precário e formação (Alves, 1998; Pais, 2001). Mas, em vez de uma alternância entre ciclos de formação e de trabalho, como em alguns países se pode verificar (Naegele et al., 2003), devido aos baixos rendimentos e à falta de incentivos do Estado e das empresas, em Portugal assiste-se muito freqüentemente a uma sobreposição de ambos, gerando claras dificuldades aos jovens, sobretudo quando pretendem encetar projetos e responsabilidades na esfera familiar. Essa transformação modificou e dramatizou, de forma acentuada, os processos de transição para a vida adulta. Muitos jovens tendem a adiar essa transição para um tempo imaginado em que a situação profissional seja mais estável e segura. A própria auto-realização no trabalho, tão proclamada como valor fundamental dos novos trabalhadores, surge então como um valor transitório, característico de um período ainda isento de grandes encargos e responsabilidades.

Mantendo-se, para a maioria dos jovens, um passo indispensável na transição para a vida adulta e independente (sobretudo num país em que os apoios estatais aos jovens são ainda muito rudimentares), o processo de entrada no mercado de trabalho transformou-se rapidamente em sentidos oblíquos. Se, por um lado, o crescimento do nível de vida das famílias, o aumento dos trabalhos qualificados e das ofertas de formação con- cedem aos jovens mais condições de valorização profissional (Lindley, 2000), ao mesmo tempo a entrada dos jovens no mercado de trabalho é, hoje, marcada pela instabilidade e pelo risco. ${ }^{3} \mathrm{O}$ aumento das taxas de desemprego e a generalização dos trabalhos precários e temporários, ambos atingindo a máxima expressão na faixa etária dos jovens (Smithson et al., 1998), empurram-nos para ciclos de inserção e desinserção, dando origem a bolsas de exclusão e, mais genericamente, ao prolongamento ou adiamento do processo de transição para a vida adulta.

Os "trabalhadores livres" da sociedade do conhecimento, integrados em projetos e redes múltiplas, tal como os trabalhadores eternamente precários ou os desempregados crônicos são, todos eles, filhos desta nova ordem social (Beck, 2000) resultante dos processos de globalização, de desenvolvimento tecnológico e de reestruturação do emprego e da economia.

\section{Reinventando a família}

Tradicionalmente, a transição para a vida adulta corresponde ao momento em que os jovens, simultaneamente, abandonam o agregado familiar de origem e casam, constituindo uma nova família. A pesquisa mostra que esse modelo continua a ser dominante em Portugal, mas a transição familiar tende a prolongar-se, complexificarse e diversificar-se, gerando uma pluralidade de situações e trajetos. Esse fenômeno inclui-se, aliás, num processo mais abrangente, verificado nas últimas décadas em Portugal, de mudanças profundas e aceleradas na esfera familiar, coexistindo hoje uma enorme diversidade de modelos e estruturas (Almeida et al., 1998).

Transformação, mas não desintegração da família, como algumas abordagens por vezes parecem fazer crer. Este estudo, entre outros recentes (Almeida e Guerreiro, 1993; Almeida, 2003), atesta bem a prevalência do "primado da família": a família permanece a principal referência para a projeção de vivências e identidades dos indiví- 
duos. Num contexto de risco, o apoio fundamental dos pais às transições para a vida adulta parece mesmo dar origem a novas solidariedades e dependências.

Para mim, é muito importante ter uma família. Família é as pessoas com que sempre podemos contar... Em princípio, essas nunca nos vão trair... aconteça o que acontecer, são aquelas pessoas que estão sempre lá... de certeza, podemos sempre contar [...]. Não estou a pensar acabar o curso e casar logo, mas passados 2 anos, mais ou menos, estou a pensar nisso. Agora, depende se tenho um emprego nessa altura (Entrevista individual: programadora informática).

Essa transformação subentende uma mudança profunda na relação entre pais e filhos, generalizando-se a situação em que os filhos permanecem até idade avançada na casa dos pais, num estatuto de "semi-dependência", nas antípodas da condição subordinada que lhes cabia na família tradicional. Na expressão de Pais (2001), muitos jovens portugueses vivem hoje no regime de welfare family. A presente investigação mostra, todavia, que essa permanência gera também inúmeros conflitos. Em particular, entre as moças e nos meios mais desfavorecidos, a independência continua a ser sinônimo de saída de casa dos pais (Brannen et al., 2002).

Mas, seguindo um padrão diferente das gerações anteriores, os jovens portugueses de hoje são muito céticos quanto ao casamento e à parentalidade precoces. Fatores culturais e econômicos cruzam-se na explicação da mudança. Tal como noutros países (Brannen e Smithson, 1998), esta via poderá ser culturalmente entendida como um constrangimento às oportunidades, às experiências pessoais ou à promoção profissional. Mas, confirmando estudos anteriores (Vasconcelos, 1998), a maioria dos jovens portugueses elegeu a insegurança profissional e a precariedade econômica como principais obstáculos à realização dos seus próprios projetos no plano familiar.

Muitos jovens criticaram mesmo aqueles que casam e têm filhos cedo, antes de alcançar uma certa "maturidade emocional e relacional" e uma situa- ção profissional mais estável. Garantir - para si próprios e, sobretudo, para os filhos - uma vida sem privações tornou-se não apenas um desejo, mas também uma obrigação, associada a uma noção detalhada da "idade certa" para ter filhos (Brannen et al., 2002). A consciência do risco cruza-se com as idéias, dominantes nesta geração, de "realização individual", "responsabilidade individual", "bem-estar material" e "infância protegida", resultando na concepção de que a parentalidade precoce constitui uma irresponsabilidade. Sobretudo nas classes qualificadas, a grande maioria dos jovens, embrenhados em trajetos escolares e acadêmicos prolongados e demonstrando ambições crescentes de cariz hedonista ou consumista, não vislumbra a hipótese de casar ou ter filhos antes dos 30 anos.

As condições para entrar na parentalidade são, geralmente, obtenção de habitação própria, independência financeira, segurança profissional e estabilidade (maturidade) relacional. Com a institucionalização da "cultura do horário prolongado”, os horários compatíveis tornam-se também, progressivamente, uma condição para o prosseguimento de projetos de parentalidade (Guerreiro, 1998). Como foi referido no tópico anterior, observa-se uma contradição clara, a saber, a insegurança dominante no mercado de trabalho e as exigências crescentes de estabilidade e bem-estar familiar e, geradora de ansiedade e bloqueio.

Neste cenário, o adiamento da transição é somente uma "meia-opção". Sendo para alguns uma escolha, fundamentada em novos padrões de vida e disposições culturais (Cavalli, 1995; Galland, 1995), para a maioria converte-se em destino, perante a impossibilidade ou a irresponsabilidade de opções alternativas. Viver sozinho ou com amigos, práticas características de transição na modernidade avançada (Galland, 1995; Prinz, 1995; Furlong e Cartmel, 1997), permanecem em Portugal quase residuais, merecendo pouco apoio estatal ou familiar. Nesses casos, a permanência em casa é entendida como um recurso imediato diante um futuro projetado ou em construção. Esses jovens encontram-se a "preparar terreno" para uma mudança que é entendida como problemática (mas 
desejada), tanto no plano econômico como no plano relacional. O que acontece em Portugal é que esta "preparação de terreno" tende a estender-se por muitos anos.

No outro extremo, uma fração minoritária mas significativa de jovens portugueses segue a via do casamento e/ou da parentalidade precoces, mesmo antes dos 20 anos. Note-se que, em 25\% dos nascimentos ocorridos em 2001, a mãe tinha menos de 25 anos e, em 43\% dos casamentos registados no mesmo ano, a nubente tinha idade inferior a 25 anos (INE, 2001). A gravidez das moças constitui, muitas das vezes, o móbil das transformações familiares registradas e, nomeadamente, do casamento. Sobre a sociedade brasileira e a sexualidade nas classes populares encontramos situações semelhantes (ver Heilborn, 1999). Todavia, se por vezes isso resulta de uma "gravidez acidental", posteriormente assumida, outras vezes decorre de uma estratégia, mais ou menos explícita, por parte dos jovens.

Engravidei quando andava no $7^{\circ}$ ano. A partir da gravidez deixei de estudar. Foi aquela adoração de ficar com ele [o bebê] (Entrevista de grupo: empregada administrativa, mãe só, a viver em casa dos pais).

Eu tinha 16 anos e estava a concluir o $9^{\circ}$ ano quando engravidei [...]. Já namorávamos desde os meus 13 anos... (Entrevista individual: secretária, a viver com o pai dos filhos).

Estratégia ou acidente, o certo é que a parentalidade e o casamento precoces parecem estar associados aos grupos sociais mais desfavorecidos. O abandono escolar, a entrada prematura no mercado de trabalho, os constrangimentos econômicos e a menor liberdade em casa dos pais conduzem uma parte significativa dos jovens das classes menos favorecidas a encetarem mais cedo projetos familiares.

Relativamente à coabitação, regista-se um fenômeno curioso. Ainda que muito freqüente nos projetos das novas classes médias, é nas classes mais desfavorecidas que alcança maior expressão em termos de práticas (Guerreiro, 1986; Lalanda,
2002; Ferreira, 2003). As condições de vida impõem a estes grupos práticas mais orientadas para o imediato e o transitório, nem sempre compatíveis com os custos e as exigências inerentes ao casamento. As carências econômicas e a relação distante com os sistemas legais tornam-se entraves à instituição matrimonial. Nesses casos, o casamento é geralmente desejado, mas adiado indefinidamente pelas contingências cotidianas. Já nos contextos populares e operários mais estabelecidos, bem como nas classes médias com poucas qualificações escolares, as disposições culturais concebem, tradicionalmente, a coabitação como sinônimo de casamento. Qualquer outra situação é entendida como desviante e ilegítima.

Quer seja pela dimensão institucional, estatutária e sagrada, no caso dos jovens de menores qualificações escolares e/ou católicos praticantes, quer seja pela carga ritual e pelo desejo de não criar conflitos com as respectivas famílias (apoios fundamentais no processo de transição), no caso dos mais escolarizados e sem filiação religiosa, o casamento continua a constituir uma prática comum nas jovens gerações em Portugal (Vasconcelos, 1998; Torres, 2002).

Apesar da enorme diversidade nos projetos e trajetos de transição para a vida adulta, a maioria dos jovens, tal como noutros países, apresentam projeções coincidentes acerca do modelo familiar desejado a longo prazo (Kugelberg, 1998; Nilsen, 1998; Lewis et al., 1999; Brannen e Nilsen, 2002; Brannen et al., 2002). A vida adulta é, assim, concebida como um período de estabilidade, em que os jovens vivem casados, em casa própria e com os filhos. Para caracterizar este modo de vida e, sobretudo, a forte interligação entre os seus vários elementos, adotou-se a designação de "pacote familiar" (Kugelberg, 1998), ilustrada neste excerto de uma estudante portuguesa:

[...] tenho planos concretos, porque há uma pessoa com quem escolhi partilhar a vida [...] essa decisão está dependente de coisas como acabar o curso, ter uma casa, trabalhar a tempo inteiro e ter meios financeiros... (Entrevista de grupo: estudante universitária). 
Não sendo mais progressista ou conservador, o novo paradigma familiar dominante é mais complexo, desenvolvendo-se a dois tempos: um primeiro período de liberdade, experiência e aventura; um segundo, de responsabilidade e estabilidade. A vivência individualizada, livre e emocionante projeta-se como espelho invertido da vida adulta, considerada rotineira, aborrecida e desinteressante. $\mathrm{O}$ mais curioso é que, quando convidados a falar dos seus planos a longo prazo, os jovens revelam a intenção de aderir a esse modelo de vida, como "trajeto natural da vida", sem proporem, aliás, alterações. Os 30 anos parecem ser a fronteira simbólica entre esses dois tempos. ${ }^{4} \mathrm{O}$ casamento tende a significar, para muitos jovens, um modo de institucionalização da transição entre um passado de liberdade e errância e um futuro que se pretende de estabilidade e responsabilidade. Ou melhor, significa um compromisso da parte do outro de que fará essa transição.

Assim, os jovens dispõem hoje não de uma via única de transição familiar, mas de uma grande diversidade de caminhos culturalmente aceita que podem (e têm de) escolher. Esta escolha permanece fortemente condicionada pelas disposições e condições proporcionadas pelos meios sociais em que se inscrevem os jovens..$^{5}$ Num contexto de contração e transformação do mercado de trabalho, essa abertura cultural vê-se freqüentemente bloqueada pela falta de oportunidades e recursos para realizar os projetos familiares pretendidos. As inseguranças associadas à transição familiar tendem, pois, a ser avaliadas e acentuadas pelos riscos vividos na esfera do trabalho.

\section{A ambivalência dos papéis femininos}

As dinâmicas da modernidade têm produzido uma relativa flexibilização dos papéis de gênero. Em Portugal, esse processo foi visível com particular intensidade e rapidez, na segunda metade do século XX. Não só a igualdade no plano legal, mas também o aumento exponencial da escolarização, das taxas de trabalho remunerado e da participação pública das mulheres têm contribuído para uma mudança efetiva e radical nas relações entre os sexos (Almeida et al., 1998). ${ }^{6}$ A generalização do acesso das mulheres às profissões altamente qualificadas - constituem já a maioria entre os profissionais técnicos e de enquadramento (Costa et al., 2000) - tem transformado significativamente as relações de poder entre os sexos, atenuando as desigualdades simbólicas e materiais entre os gêneros (O'Connor et al., 2002).

Aliás, Portugal registra taxas muito elevadas de trabalho feminino, acompanhando os países do norte da Europa e em forte contraste com os outros países da Europa do Sul (Almeida et al., 1998). Mas, ao contrário daquilo que acontece nos países nórdicos, o trabalho a tempo parcial ou em casa e as licenças prolongadas são ainda modalidades com muito pouca expressão em Portugal, pelo que o grupo específico das "mães com filhos pequenos" registra uma taxa de atividade a tempo integral mais elevada da Europa (Eurostat, 2002). Enquanto as disposições culturais tendem a considerar a profissionalização feminina geralmente desejável, sobretudo nos setores mais escolarizadas da população (Torres e Silva, 1998), os constrangimentos econômicos da grande maioria das famílias portuguesas tornam o trabalho feminino inevitável.

No entanto, a generalização do trabalho feminino coexiste com a persistência de fortes assimetrias entre sexos nas condições e nas oportunidades conferidas no plano profissional. Nas entrevistas realizadas, as jovens portuguesas, tal como por exemplo as irlandesas, denunciam a discriminação de que são alvo no mercado de trabalho (Lewis et al., 1999). As recentes transformações - em particular, a escassez de postos de trabalho e a ênfase quer na informalidade quer na mobilidade - podem, aliás, também fragilizar a condição laboral feminina.

Essa duplicidade na reconstrução dos papéis de gênero reflete-se seja nas representações dos jovens entrevistados, seja nas suas biografias. Enquanto uns salientam a convergência de representações e aspirações e a renegociação dos papéis de gênero (Idem), perante um contexto tradicio- 
nal de fortes assimetrias, outros enfatizam a persistência de desigualdades e discriminação em vários contextos sociais. Por outro lado, enquanto uns revelam trajetos de vida claramente marcados pelo fator gênero, outros parecem apresentar percursos de vida relativamente "unisexo".

As inúmeras discussões, nas entrevistas de grupo, em torno dos projetos de vida atestam bem este fato. Mais do que uma verdadeira clivagem de orientações e prioridades, o que acontece é que, enquanto para os rapazes os projetos profissionais e familiares surgem em continuidade, visto que suas principais responsabilidades se relacionam com a segurança econômica, para as moças, há uma óbvia dificuldade em conciliar ambas as esferas, sendo, portanto, obrigadas a escolher a qual delas darão prioridade. A visão de que homens e mulheres têm orientações e aspirações diferentes na vida - homens preocupam-se com as questões profissionais; mulheres dedicam-se às questões familiares, domésticas e afetivas - encontra-se ainda inscrita na "ordem natural das coisas" para muitos dos jovens europeus entrevistados, sobretudo aqueles que pertencem às classes mais desfavorecidas e menos escolarizadas (Lewis et al., 2002b; Lewis et al., 1999). A popularidade do argumento biologicista, segundo o qual as mulheres são mais práticas e afetivas, tendo objetivos mais bem definidos, deve então ser interpretada à luz das menores oportunidades de que dispõem e, por conseguinte, da necessidade que sentem de manter disposições mais flexíveis e contingentes. Como comentou uma das jovens entrevistadas, "às mulheres acontece-lhes muitas vezes isso: têm que abdicar do que escolheram fazer ou, por vezes, mudar".

Assim, as altas taxas de trabalho profissional feminino coexistem com a prevalência de um modelo claramente assimétrico de relação conjugal e, em particular, de divisão das tarefas domésticas. Essa realidade encontra-se amplamente documentada em estudos sociológicos recentes, que enfatizam o fato de as mulheres portuguesas cumprirem uma "dupla jornada de trabalho" (Almeida et al., 1998; Torres e Silva, 1998; Wall e Guerreiro, 2005).
Nesse sentido, a realidade portuguesa quanto às relações de gênero é muito particular no quadro europeu, dificilmente se enquadrando no binômio tradicional versus moderno.

A maioria dos rapazes, pouco habituados a realizar as tarefas domésticas na casa dos pais, olhaas com desagrado e/ou desconhecimento. Como comentou uma das jovens entrevistadas, na maioria das casas, "a filha tem que fazer, o filho coitadito, vamos poupá-lo”. A socialização diferencial tende, pois, a facilitar a reprodução dos papéis de gênero. Essa assimetria no desempenho das tarefas domésticas é, aliás, apontada pelas jovens já casadas como um foco de insatisfação e de conflito freqüente.

Eu acho que, se nós os dois trabalhamos, então nós os dois devemos assumir em casa.... dividir tudo a meias. Porque se eu trabalho, tu trabalhas, se eu chego a casa às 8 ou às 10 , se tu chegas a casa às 7 , não vais sentar-te no sofá a ver televisão. Porque é isso que acontece com o meu marido... [ele] não dá de comer aos filhos, não muda a fralda, não os veste, não dá banho [...]. E depois uma pessoa chega a um certo ponto e está farta. Porque eu tenho que fazer tudo (Entrevista individual, jovem empregada na restauração).

Entre os rapazes menos qualificados, as tarefas domésticas são consideradas atividades exclusivamente femininas, ainda que por vezes as contingências da vida os obriguem a desempenhar algumas delas em casa (Guerreiro, 1986). Os rapazes mais qualificados são mais vagos, referindo mesmo que as "empregadas domésticas" constituem a única solução satisfatória em face da dificuldade e da injustiça de o trabalho doméstico ser apenas assegurado pelas mulheres. Em todo O caso, a sugestão de que "ajudam" ou "irão ajudar" as mulheres é geralmente entendida como suficiente, mantendo implícito que as mulheres continuam a desempenhar o grosso das tarefas domésticas.

Nesse sentido, a questão da conciliação entre vida profissional e vida familiar permanece, essencialmente, uma questão feminina. Apenas para as mulheres essa conciliação é encarada como pro- 
blemática ou potencialmente impossível, visto que são elas que assumem as principais responsabilidades familiares. A definição da família como prioridade coexiste, em muitos casos mal, com o crescimento das aspirações escolares e profissionais. Um grupo significativo de moças declarou abdicar da vida familiar, uma vez que não a considerava conciliável com os seus exigentes cotidianos e aspirações profissionais. No caso dos rapazes, os condicionalismos profissionais, geográficos ou de horários, são aceitos como inevitáveis e raramente entendidos como entraves à vida familiar.

No presente estudo tornou-se notório que o processo de transição para a vida adulta, nas sociedades contemporâneas, envolve um transformação profunda das identidades e das relações de gênero. Esta parece constituir uma problemática complexa mas profícua para futura análise sociológica. Durante a adolescência, a melhor integração das moças nas esferas escolar e familiar traduz-se numa vantagem simbólica temporária em relação aos rapazes, os quais parecem cair mais facilmente numa dinâmica de exclusão social. Mesmo no âmbito das práticas de sociabilidade e dos estilos de vida, ainda que mais condicionadas, as moças tendem hoje a demonstrar opções e aspirações semelhantes ou, pelo menos, equivalentes às dos rapazes. Mas, volvidos alguns anos, as mulheres continuam a ser subalternizadas e discriminadas quer no contexto de trabalho, isto é, como trabalhadoras, quer no plano familiar, como esposas e mães.

Existe, pois, uma defasagem significativa tanto material como simbólica - entre as relações de gênero estabelecidas nessas duas fases de vida, dando origem a processos de recomposição identitária e relacional particularmente complexos e que nem sempre são vividos pelos atores sociais de forma pacífica. Esta constatação enquadra-se, aliás, na idéia mais geral de que, atualmente, o processo de individualização ocorre, sobretudo, num período transitório, sendo sucedido por uma certa estabilização nos padrões de vida mais convencionais (Nilsen, 1998; Nilsen e Brannen, 2002).

Mecanismos mais sutis tendem, pois, a (re)construir os papéis de gênero, permitindo o aces- so legítimo das mulheres a um conjunto de direitos e esferas sociais mas, simultaneamente, a reprodução das desigualdades de poder entre os sexos (Amâncio, 1994; Bourdieu, 1998).

\section{Percursos de transição para a vida adulta}

Neste tópico, propomos uma tipologia que inclui sete padrões diferenciados de transição para a vida adulta na sociedade portuguesa atual, com base na análise transversal dos trajetos (e projetos) de vida, a partir da realização de entrevistas individuais e de grupo.

Recuperando a metodologia weberiana de definição de tipos-ideais, esta tipologia pretende mostrar, por um lado, como esses percursos deixaram de corresponder a uma via única idealizada, tornando-se múltiplos e problemáticos, mas, por outro lado, como permanecem associados a um número finito de padrões, lógicas ou referenciais sociais, não correspondendo a meras escolhas pessoais ou derivas erráticas. ${ }^{7}$

Pretende-se, desta forma, analisar as formas complexas por meio das quais, nas trajetórias e identidades (singulares e integradas) dos jovens, se articulam as suas vivências nos vários campos sociais. Esta análise é multi-dimensional, de modo a conceber a relação entre vários campos (educação, família, trabalho, lazeres), e longitudinal, visto que as transições para a vida adulta constituem, cada vez mais, percursos prolongados, em vez de passagens imediatas.

\section{Transições profissionais}

Neste modelo, os jovens caracterizam-se por um investimento quase exclusivo no trabalho, nos primeiros anos, relegando os projetos familiares ou de lazer para um futuro mais ou menos longínquo. Alguns não demonstram grandes ambições no plano familiar, mas a maioria pretende adquirir o "pacote familiar" quando tiver assegurado um 
estatuto profissional mais estável. Em face da incerteza e da exigência do mercado de trabalho, apostam numa transição a "dois tempos". As recentes dinâmicas de precariedade e mobilidade que regem o sistema de emprego, bem como a "cultura do horário prolongado", vão adiando indefinidamente este ensejo, levando-os a viver em "presentes prolongados" (Brannen e Nilsen, 2002; Lewis et al., 2002a), em geral na casa dos pais até uma idade tardia, sob um estatuto de semi-dependência.

\section{Transições lúdicas}

Estes jovens caracterizam-se por um longo período pós-adolescente destinado a viver a vida de forma descontraída, emocionante e sem grandes preocupações, sob o signo da fruição e da errância. A sua prioridade é conhecer locais distantes, conviver com os amigos, sair à noite, procurar novas experiências e sensações, aprender e divertir-se, antes de assentar e assumir responsabilidades. Em geral, caracterizam-se por longos trajetos de escolaridade e inserções precárias e/ou temporárias no mercado de trabalho, que não implicam grandes compromissos e responsabilidades. Quase sempre, estes jovens permanecem até uma idade tardia na casa dos pais, gozando de um estatuto de "semi-dependência", com liberdades quase ilimitadas e encargos financeiros quase nulos, mas refletindo também dificuldade na obtenção da independência financeira (Nilsen et al., 2002). Alguns autores têm tomado este como um traço geracional, associado à melhoria das condições de vida das famílias e à contração do mercado de trabalho, mas também a novas disposições culturais, que valorizam a individualização e a realização pessoal, pelo menos durante o período da transição para a vida adulta (Cavalli, 1995; Galland, 1995; Du Bois, 1995). Mas em Portugal, os constrangimentos econômicos e culturais levam a que este seja ainda um modelo muito minoritário, que permanece quase exclusivo ao mundo masculino.
Transições experimentais

Estes percursos caracterizam-se por uma sucessão de configurações de vida temporárias e imprevisíveis, como opção de vida ou como período de experimentação antes de "assentar", casar e ter filhos. À semelhança do que acontece nas sociedades mais avançadas (Galland, 1995; Furlong e Cartmel, 1997), viver sozinho, em coabitação ou com um grupo de amigos tornam-se modelos culturalmente valorizadas, pelo menos até à parentalidade, nos setores mais escolarizados da população. Ainda assim, em Portugal, não só existe alguma resistência (cultural) de largos setores da sociedade (incluindo parte dos jovens), como também o apoio público ou familiar a trajetos deste tipo são claramente insuficientes. O elevado preço das habitações e a condição mais ou menos precária no mercado de trabalho conduzem a esmagadora maioria dos jovens a atenuar muito o experimentalismo mesmo no período de transição para a vida adulta, tornando-se este um ideal partilhado mas uma prática quase residual.

\section{Transições progressivas}

Este modelo, muito freqüente entre os jovens portugueses, caracteriza-se por formas de transição relativamente lineares e programadas, em que o percurso de escolaridade antecede a progressiva integração profissional e a esta sucede a constituição de família. Aliás, ante a insegurança crescente na esfera do trabalho, os modelos progressivos e planeados de transição tendem a ser defendidos como estratégia de gestão do risco (Brannen e Nilsen, 2002). Considerando que a etapa de "progressão na carreira" encontra-se hoje bastante obstruída, a passagem para as etapas seguintes tende a ser dificultada, causando um prolongamento dessas trajetórias de transição. Para muitos dos jovens portugueses, sobretudo das classes desfavorecidas, as "transições progressivas" representam a "transição bem-sucedida", pois asseguram um certo bem-estar ao longo das várias 
etapas percorridas. Num contexto de trabalho marcado pela precariedade, num contexto familiar e amoroso marcado pela negociação constante, as transições estáveis e lineares constituem uma conquista árdua, contra as contingências imprevisíveis do cotidiano.

\section{Transições precoces}

Este modelo corresponde à passagem rápida e numa idade precoce de um estatuto de dependência na casa dos pais, ao estatuto de trabalhador, em vida conjugal, muitas vezes com filhos e desejavelmente (mas nem sempre) em casa própria. Em Portugal, continua a ser freqüente, sobretudo entre as moças das classes desfavorecidas (Nilsen et al., 2002). A maior incidência de "transições precoces" entre as moças reflete ainda uma forte diferenciação entre o papel masculino, marcado por mais oportunidades de lazer e responsabilidades profissionais, e o feminino, sujeito a maior controle familiar, do qual só se consegue libertar por meio da constituição de nova família. As fracas aspirações escolares, a entrada precoce no mercado de trabalho, as limitações na esfera do lazer e do consumo, o maior controle familiar a que estão sujeitos e o menor planejamento familiar são razões que conduzem, freqüentemente, os jovens das classes desfavorecidas a seguir este tipo de transição, após uma passagem curta e periférica pelo universo juvenil (Bourdieu, 1984).

\section{Transições precárias}

Este modelo corresponde a percursos de constante (re)adaptação dos jovens aos constrangimentos que lhes vão sendo impostos, denotando campos de possibilidade e de opção muito reduzidos. Se existem hoje muito mais oportunidades e opções, estas encontram-se longe de estar acessíveis a todos os segmentos do universo juvenil. Mais, as situações de insegurança e precariedade vividas em diversos setores do mercado de trabalho geram no- vos riscos e constrangimentos, condicionando os projetos e os trajetos de vida dos jovens (Casal, 1997; Lewis et al., 2002b; Brannen et al., 2002). Em geral, os jovens com "transições precárias" fazem parte da massa de "trabalhadores descartáveis", que se encontram hoje na área cinzenta entre a inserção efetiva no mercado de trabalho e a desinserção de longo prazo (Beck, 1992, 2000; Castells, 1996).

\section{Transições desestruturantes}

Este modelo caracteriza-se pela incapacidade, revelada por alguns grupos de jovens, para a construção de uma transição para a vida adulta e independente, mergulhando em espirais de exclusão social, com a quebra de uma série de vínculos sociais e, potencialmente, sentimentos de depressão aguda e/ou experiências de marginalidade social. Esses processos podem surgir de uma miríade de razões, entre as quais devemos hoje salientar o desemprego de longa duração. ${ }^{8}$ Note-se que a modernidade tardia se caracteriza por uma enorme expansão das oportunidades individuais mas também dos riscos (Beck, 1992, 2000). Na transição para a vida adulta, os jovens podem construir biografias intensamente individuais, aproveitando as múltiplas opções que têm ao seu dispor, mas podem também cair em "buracos negros", condições degradantes marcadas pela precariedade, isolamento e ausência de oportunidade. A informalidade e a flexibilidade das diversas instituições (e das formas de transição entre elas) oferecem uma grande liberdade, mas também riscos suplementares, sobretudo porque as instituições tendem a delegar aos indivíduos a responsabilidade sobre tudo aquilo que lhes acontece. Note-se que a exclusão social tende a ser um processo gradual, em que os vários fatores se vão sobrepondo e reforçando. Nesse sentido, o insucesso escolar, o desemprego, a desintegração familiar, a marginalidade são fatores que, mesmo não estando sempre presentes, tendem a acumular-se em trajetos desestruturados, marcados pela privação de recursos, oportunidades e projetos. 


\begin{tabular}{|c|c|c|c|c|c|}
\hline \multicolumn{6}{|c|}{$\begin{array}{l}\text { Quadro } 1 \\
\text { :ansição para a Vida Adulta }\end{array}$} \\
\hline $\begin{array}{l}\text { Padrões de } \\
\text { transição }\end{array}$ & Origem social & Escolaridade & $\begin{array}{l}\text { Integração pro- } \\
\text { fissional }\end{array}$ & $\begin{array}{l}\text { Modo de resi- } \\
\text { dência }\end{array}$ & Orientação \\
\hline Profissional & Diversificada & Elevada & Forte & Em casa dos pais & Trabalho \\
\hline Lúdica & $\begin{array}{l}\text { Classes } \\
\text { médias/altas }\end{array}$ & $\begin{array}{l}\text { Elevada/interme- } \\
\text { diária }\end{array}$ & Instável & Em casa dos pais & Lazer \\
\hline Experimental & $\begin{array}{l}\text { Classes mé- } \\
\text { dias/altas }\end{array}$ & Elevada & Regular/instável & $\begin{array}{l}\text { Espaços transitó- } \\
\text { rios }\end{array}$ & Self \\
\hline Progressiva & Diversificada & Diversificada & Progressiva & Em casa dos pais & Futuro \\
\hline Precoce & $\begin{array}{l}\text { Classes } \\
\text { desfavorecidas }\end{array}$ & Baixa & Instável & Em casa própria & $\begin{array}{l}\text { Responsabilidade } \\
\text { familiar }\end{array}$ \\
\hline Precária & $\begin{array}{l}\text { Classes } \\
\text { desfavorecidas }\end{array}$ & Baixa & Instável & Em casa dos pais & Adaptativa \\
\hline Desestruturante & $\begin{array}{l}\text { Classes } \\
\text { desfavorecidas }\end{array}$ & $\begin{array}{l}\text { Baixa/intermediá- } \\
\text { ria }\end{array}$ & Periférica & $\begin{array}{l}\text { Espaços transitó- } \\
\text { rios }\end{array}$ & Sobrevivência \\
\hline
\end{tabular}

\section{Considerações finais}

A transição para a vida adulta encontra-se na ordem do dia, nas sociedades avançadas, em grande medida porque nela se refletem com particular intensidade os principais fluxos de transformação social, incluindo oportunidades originais, estilos de vida inovadores, mas também novos focos de desequilíbrio, desigualdade e exclusão social.

Tendo surgido nos anos de 1970 como preocupação pública, o tema das transições para a vida adulta tem conhecido recentemente um maior interesse por parte das ciências sociais. Não apenas se tornou consensual que essa transição constitui um processo intensamente social, mas também se considera, hoje, que ela é um eixo de estruturação quer das identidades quer das sociedades, bem como um campo fértil e fascinante para o pensamento sociológico. Como sugerem Banks et al. (1992), fenômenos sociais que nos habituamos a pensar como distantes - educação, ocupação profissional, família, política, cultura ou sociabilidades - surgem profundamente entrelaçados em complexos percursos biográficos e de (re)construção identitária. Em vez de estudar um grupo ou uma condição, explora processos ou trajetórias, o que conduz a uma abordagem, simultaneamente, transversal e diacrônica.

Constituindo não um momento de passagem, mas sim um percurso, as transições para a vida adulta tornam-se um espaço original para a produção e a reprodução de práticas e representações específicas, um espaço identitário. A pesquisa mostrou que, em vez de uma passagem simples entre dois estatutos ou de um continuum caótico de mudanças, o período de transição tende a constituir, por si próprio, uma fase de vida, marcada por condições, oportunidades e dificuldades próprias. É neste sentido que parece apropriado, hoje em dia, entender a transição para a vida adulta como um percurso "a dois tempos": um primeiro período isento de grandes preocupações e dedicado a experiências e aventuras; um segundo dominado pela estabilidade e pela responsabilidade, no qual se pensa em casar e ter filhos.

Além disso, o presente estudo sugere que, apesar das tendências de diversificação e não-linearidade, é possível identificar "padrões de transição". Esses padrões são resultado de processos de reflexividade social, mas não são meras opções disponíveis a todos, entrelaçando-se com as origens sociais, os percursos de escolaridade, as oportunidades e as condições de emprego, os modelos culturais, os papéis de gênero e as redes de apoio formais e informais. Assim como proporcionam múltiplas oportunidades e vias alternativas, os processos de transição para a vida adulta ocorrem hoje num contexto de risco.

Este contexto de imprevisibilidade, misto de oportunidades e riscos, levou-nos ao conceito de 
"transições incertas". Presente na vida de quase todos os jovens em transição, a incerteza assume formas muito diversas, refletindo condições e oportunidades muito distintas e assimétricas. Se, para uns, a incerteza resulta sobretudo das múltiplas vias disponíveis, para muitos outros, essa incerteza deriva da incapacidade, prolongada no tempo, de superar os contextos sociais precários e de risco em que se encontram mergulhados.

\section{NOTAS}

1 Esta investigação, agora numa segunda fase, iniciada em 2003, inscreve-se num projeto europeu coordenado por Suzan Lewis, da Manchester Metropolitan University, e com pesquisas semelhantes em vários países: Inglaterra, Irlanda, Noruega, Suécia e Portugal. No presente, a equipe integra também França, Holanda, Eslovénia e Bulgária.

2 Assalariados de base administrativos, do comércio, dos serviços pessoais e domésticos etc.

3 Espelho invertido da estrutura de oportunidades, a estrutura do risco é fortemente assimétrica. Além da importância inegável das qualificações escolares, as posições e as oportunidades nos mercados de trabalho continuam a ser muito condicionadas pelas redes pessoais e informais. Diversos estudos têm mostrado como a ajuda de familiares, amigos ou conhecidos é o principal meio de obtenção de emprego (Santos, 1989; Guerreiro et al., 2000).

4 Em Nobres \& Anjos, Gilberto Velho (1998) utiliza esta mesma fronteira etária para se referir à demarcação entre os grupos de jovens que estudou na Zona Sul do Rio de Janeiro e as gerações mais velhas, freqüentadoras dos mesmos espaços públicos.

5 Neste mesmo sentido vão as reflexões de Gilberto Velho (2002) quando se refere "à ideia do sujeito atuando, operando e optando" como dominante, mas que "há que nuançar", em face dos "vários casos evidentes da importância crucial das famílias de origem na efetivação de certos matrimônios".
6 Não há dúvida de que, além dos movimentos feministas, a escola tem contribuído de forma efetiva para uma subversão parcial da "dominação masculina", constituindo um poderoso espaço de valorização das identidades femininas. Atualmente, em Portugal, resultado de fluxos contraditórios, as mulheres registram valores mais elevados que os homens quer nos setores menos qualificados da população (analfabetos, sem escolaridade, $1^{\circ}$ ciclo) quer nos setores mais qualificados (ensino superior).

7 É importante não esquecer que, tal como frisava Weber (1922), estes modelos devem ser entendidos como referências - sociais (porque orientam os atores) e sociológicas (porque orientam os sociólogos) de uma certa realidade e não como $a$ realidade strictu sensu, povoada de complexidades e singularidades.

8 Longe de ser residual, o desemprego de longa duração constitui atualmente um grave problema nas sociedades européias, alcançando a máxima expressão entre os jovens (Lindley, 2000). Mais do que a precariedade das condições de vida dos jovens (que pode ser atenuada por subsídios), o desemprego de longa duração constitui geralmente uma experiência dramática de isolamento, contração das oportunidades nos vários campos sociais e desestruturação de identidades, projetos e sociabilidades (Santos, 1989; Banks et al., 1992; Pais, 1993).

\section{BIBLIOGRAFIA}

ALMEIDA, Ana Nunes de. (2003), "Família, conjugalidade e procriação: valores e papéis", in Jorge Vala et al. (orgs.), Atitudes sociais dos portugueses: valores sociais mudanças e contrastes, Lisboa, ICS.

ALMEIDA, Ana Nunes de \& GUERREIRO, Maria das Dores. (1993), "A família”, in Luís de França, Portugal, valores europeus, identidade cultural, Lisboa, IED.

ALMEIDA, Ana Nunes de; GUERREIRO, Maria das Dores; LOBO, Cristina; TORRES, Anália 
\& WALL, Karin. (1998), "Relações familiares: mudança e diversidade", in José Leite Viegas e António Firmino da Costa (orgs.), Portugal, que modernidade?, Oeiras, Celta, pp. 45-78.

ALMEIDA, João Ferreira de. (1990), Valores e representações sociais. Lisboa, Fundação Calouste Gulbenkian ("Portugal: Os Próximos 20 Anos”, vol. VIII).

ALMEIDA, João Ferreira; ÁVILA, Patrícia; CASANOVA, José Luís; COSTA, António Firmino da; MACHADO, Fernando Luís; MARTINS, Susana \& MAURITTI, Rosário. (2000), Diversidade na universidade: um inquérito aos estudantes de licenciatura, relatório de projeto, Lisboa, Cies/ISCTE.

ALVES, Natália. (1998), "Escola e trabalho: atitudes, projectos e trajectórias", in Manuel Vilaverde Cabral e José Machado Pais (orgs.), Jovens portugueses de hoje, Oeiras, Celta, pp. 53-133.

AMÂNCIO, Lígia. (1994), Masculino e feminino: $a$ construção social da diferença. Porto, Afrontamento.

BANKS, Michael; BATES, Inge; BREAKWELL, Glynis; BYNNER, John; EMLER, Nicholas; JAMIESON, Lynn \& ROBERTS, Kenneth. (1992), Careers \& identities. Milton Keynes, Open University Press.

BAUMAN, Zygmunt. (1999), Work, consumerism and the new poor. Buckingham, Open University Press.

BECK, Ulrich. (1992), Risk society: towards a new modernity. Londres, Sage.

. (2000), The brave new world of work. Cambridge, Polity Press.

BENAVENTE, Ana; CAMPICHE, Jean; SEABRA, Teresa \& SEBASTIÃO, João. (1994), Renunciar à escola: o abandono escolar no ensino básico. Lisboa, Fim-de-Século.
BOURDIEU, Pierre. (1984), "La jeunesse n'est qu'un mot", in Questions de sociologie, Paris, Éditions de Minuit.

(1998/1999), A dominação masculina. Oeiras, Celta.

BRANNEN, Julia; DODD, Kathryn; OAKLEY, Ann \& STOREY, Pamela. (1994), Young people, bealth and family life. Buckingham, Open University Press.

BRANNEN, Julia \& SMITHSON, Janet. (1998), "Conciliação entre o trabalho e os filhos: perspectivas de futuro para jovens de cinco países". Sociologia, Problemas e Práticas, 27: 11-25.

BRANNEN, Julia \& NILSEN, Ann. (2002), "Young people's perspectives on the future", in Julia Brannen, Suzan Lewis, Ann Nilsen e Janet Smithson (orgs.), Young europeans, work and family, Londres, Routledge, pp. 48-68.

BRANNEN, Julia; KUGELBERG, Clarissa; GUERREIRO, Maria das Dores \& Smithson, Janet. (2002), "Imagining parenthood and employment: connected or disconnected worlds?", in Julia Brannen, Suzan Lewis, Ann Nilsen e Janet Smithson (orgs.), Young europeans, work and family, Londres, Routledge, pp. 116-139.

CASAL, Joaquim. (1997), "Modos emergentes de transición a la vida adulta en el umbral del siglo XXI: aproximación sucesiva, precaridad y desestructuración”, in José Machado Pais e Lynne Chrisholm (orgs.), Jovens em mudança. Actas do Congresso Growing up between Centre and Periphery, Lisboa, ICS.

CASTELLS, Manuel. (1996), The rise of network society, (Information Age: Economy, Society and Culture, vol. I), Blackwell.

. (1998), End of millenium, (Information Age: Economy, Society and Culture, vol. III), Blackwell. 
CAVALLI, Alessandro. (1995), "Prolonging youth in Italy: being in no hurry", in Alessando Cavalli e Olivier Galland (orgs.), Youth in Europe, Londres, Pinter, pp. 24-32.

CLEGG, Stewart. (1998), As organizações modernas. Oeiras, Celta Editora.

CORDEIRO, João Pedro. (2002), "Modalidades de inserção profissional dos quadros superiores nas empresas". Sociologia, Problemas e Práticas, 38.

COSTA, António Firmino da; MACHADO, Fernando Luís \& ALMEIDA, João Ferreira de. (1990), "Estudantes e amigos, trajectórias de classe e redes de sociabilidade". Análise social, ICS, 105-106.

COSTA, António Firmino da; MAURITTI, Rosário; MARTINS, Susana; MACHADO, Fernando Luís \& ALMEIDA, João Ferreira de. (2000), "Classes sociais na Europa". Sociologia, Problemas e Práticas, 34: 9-43.

DU BOIS, Raymond. (1995), "Future orientations of dutch youth: the emergence of a choice biography", in Alessandro Cavalli e Olivier Galland (orgs.), Youth in Europe, Londres, Pinter, pp. 79-93.

EUROSTAT. (2002), "L'influence des enfants sur le travail des femmes". Embargo, 60.

FERREIRA, Pedro Moura. (2003), "Tendências e modalidades da conjugalidade". Sociologia, Problemas e Práticas, 43.

FREIRE, João. (1998), "Empresas e organizações: mudanças e modernização", in José Leite Viegas e António Firmino da Costa (orgs.), Portugal, que modernidade?, Oeiras, Celta, pp. 285-309.

FURLONG, Andy \& CARTMEL, Fred. (1997), Young people and social change: individualization and risk in late modernity. Buckingham/Filadélfia, Open University Press.
GALLAND, Olivier. (1995), "Youth in France", in Alessandro Cavalli e Olivier Galland (orgs.), Youth in Europe, Londres, Pinter, pp. 7-22.

GARCIA, José Luís; JERÓNIMO, Helena Mateus; NORBERTO, Rui \& AMARO, Maria Inês. (2000), Estranhos: juventude e dinâmicas de exclusão social em Lisboa. Oeiras, Celta.

GIDDENS, Anthony. (1992/1995), Transformações da intimidade: sexualidade, amor e erotismo nas sociedades modernas. Oeiras, Celta.

GRÁCIO, Sérgio. (2000), "Educação e emprego: reflexões suscitadas pela semana da juventude", in Educação, formação e trabalbo: debate promovido pela presidência da República, Lisboa, Imprensa Nacional Casa da Moeda, pp. 129-138.

GUERREIRO, Maria das Dores. (1986), Mulheres do fado, fados de mulher-Alfama: o tecido social, as práticas culturais e as suas protagonistas. Lisboa, ISCTE/PAPCC. (1998), "Transição para a vida adulta dos jovens portugueses", in Maria das Dores Guerreiro (org.), Trabalho, familia e gerações: conciliação e solidariedades, Lisboa, CIES/ISCTE, pp. 121-130. . (2003), "Pessoas sós: múltiplas realidades". Sociologia, Problemas e Práticas, 43 .

GUERreIro, Maria das Dores; PEGADO, Elsa; RODRIGUES, Nuno \& SALEIRO, Sandra. (2000), Relações sócio-laborais em micro e pequenas empresas. Lisboa, OEFP.

HANDY, Charles. (1986), El futuro del trabajo bumano. Barcelona, Ariel.

HEILBORN, Maria Luiza. (1999), "Construção de si, género e sexualidade", in Maria Luiza Heilborn (org.), Sexualidade, Rio de Janeiro, Jorge Zahar Editor. 
INE, Instituto Nacional de Estatística. (2001), Censos 2001. Resultados definitivos: XIV recenseamento geral da população, Lisboa, INE.

(2004), Estatísticas do emprego, http//www.ine.pt.

JENKINS, Clive \& SHERMAN, Barrie. (1979), The collapse of work. Londres, Eyre Methuen.

KAUFMANN, Jean-Claude. (1992, 2002), O labirinto conjugal: o casal e o seu guardaroupa. Lisboa, Editorial Notícias.

KUGELBERG, Clarissa. (1998), "Imagens culturais dos jovens suecos acerca do início da vida adulta". Sociologia, Problemas e Práticas, 27.

LALANDA, Piedade. (2002), "Casar pelo civil ou na igreja”. Sociologia, Problemas e Práticas, 39: 69-83.

LEWIS, Suzan; SMITHSON, Janet; BRANNEN, Julia; GUERREIRO, Maria das Dores; KUGELBERG, Clarissa; NILSEN, Ann \& O'CONNOR, Pat. (1999), Futuros em suspenso: jovens europeus falam acerca da conciliação entre trabalho e família. Lisboa, ISCTE.

LEWIS, Suzan; SMITHSON, Janet \& KUGELBERG, Clarissa. (2002a), "Into work: job insecurity and changing psychological contracts", in Julia Brannen, Suzan Lewis, Ann Nilsen e Janet Smithson (orgs.), Young europeans, work and family, Londres, Routledge, pp. 69-88.

LEWIS, Suzan; SMITHSON, Janet \& GUERREIRO, Maria das Dores (2002b), "Into parenthood: young people sense of entitlement to support for the reconciliation of employment and family life", in Julia Brannen, Suzan Lewis, Ann Nilsen e Janet Smithson (orgs.), Young europeans, work and family, Londres, Routledge, pp. 140-161.
LINDLEY, Robert. (2000), "Economias baseadas no conhecimento: o debate europeu num novo contexto", in Maria João Rodrigues, Robert Boyer, Manuel Castells, Gøsta Esping-Andersen e Robert Lindley (orgs.), Para uma Europa da inovação e do conhecimento: emprego, reformas económicas e coesão social, Oeiras, Celta.

MACHADO, Fernando Luis \& COSTA, António Firmino. (1998), "Processos de uma modernidade inacabada", in José Leite Viegas e António Firmino da Costa (orgs.), Portugal, que modernidade?, Oeiras, Celta.

MAURITTI, Rosário. (2002), "Padrões de vida dos estudantes universitários nos processos de transição para a vida adulta". Sociologia, Problemas e Práticas, 39: 85-116.

MORTIMER, Joylin; HARLEY, Carolyn \& ARONSON, Pamela. (1999), "How do prior experiences in the workplace set the stage for transitions to adulthood", in Alan Booth, Ann Crouter e Michael Shanahan (orgs.), Transitions to adulthood in a changing economy: no work, no family, no future, Westport, Praeger, pp. 131-159.

NAEGELE, Gerhard et al. (2003), A new organisation of time over working life. Dublin, European Foundation for the improvement of living and working conditions.

NEVES, António Oliveira. (2000), "Valorização dos recursos humanos: desafios da educação e formação contínua", in Educação, formação e trabalbo: debate promovido pela presidência da República, Lisboa, Imprensa Nacional Casa da Moeda, pp. 119-127.

NILSEN, Ann. (1998), "Jovens para sempre? Uma perspectiva da individualização centrada nos trajectos de vida". Sociologia, Problemas e Práticas, 27: 59-78.

NILSEN, Ann \& BRANNEN, Julia. (2002), "Theorising the individual-structure dynamic", 
in Julia Brannen, Suzan Lewis, Ann Nilsen e Janet Smithson (orgs.), Young europeans, work and family, Londres, Routledge, pp. 30-47.

NILSEN, Ann; GUERREIRO, Maria das Dores \& BRANNEN, Julia. (2002), "Most choices involve money: different pathways to adulthood", in Julia Brannen, Suzan Lewis, Ann Nilsen e Janet Smithson (orgs.), Young europeans, work and family, Londres, Routledge, pp. 162-182.

O'CONNOR, Pat; SMITHSON, Janet \& GUERREIRO, Maria das Dores. (2002), "Young people's awareness of gendered realities", in Julia Brannen, Suzan Lewis, Ann Nilsen e Janet Smithson (orgs.), Young europeans, work and family, Londres, Routledge, pp. 89-115.

PAIS, José Machado.(1993), Culturas juvenis. Lisboa, Imprensa Nacional-Casa da Moeda. . (2001), Ganchos, tachos e biscates: jovens, trabalbo e futuro. Porto, Ambar.

PEIXOTO, João. (1999), A mobilidade internacional dos quadros: migrações internacionais, quadros e empresas transnacionais em Portugal. Oeiras, Celta.

PRINZ, Cristopher. (1995), Cohabiting: married, or single. Aldershot, Avebury.

RAMOS, Elsa. (2002), Rester enfant, devenir adulte: la cohabitation des étudiants chez leurs parents. Paris, L'Harmattan.

REICH, Robert. (1993), O trabalho das nações. Lisboa, Quetzal.

RIFKIN, Jeremy. (1995), La fin du travail. Paris, La Découverte.

SANTOS, Félix Riquena. (1989), Amigos y redes sociales: elementos para una sociología de la amistad. Madrid, CIS/Siglo Veintiuno (col. Monografias, 139).

SANTOS, Boaventura Sousa. (2001), "Os processos da globalização", in Boaventura
Sousa Santos (org.), Globalização: fatalidade ou utopia?, Porto, Afrontamento, pp. 31-106.

SEABRA, Teresa. (1999), Educação nas famílias: etnicidade e classes socais. Lisboa, Instituto de Inovação Educacional.

SENNETT, Richard. (1999), The corrosion of character: the personal consequences of work in the new capitalism. Nova York, W.W. Norton \& Company.

SMITHSON, Janet; LEWIS, Suzan \& GUERREIRO, Maria das Dores. (1998), "Percepções dos jovens sobre a insegurança no emprego e suas implicações no trabalho e na vida familiar". Sociologia, Problemas e Práticas, 27: 97-113.

SUPIOT, Alain. (2001), Beyond employment. Oxford, Oxford University Press.

TORRES, Anália. (2002), Casamento em Portugal: uma análise sociológica. Oeiras, Celta.

TORRES, Anália \& SILVA, Francisco. (1998), "Guarda das crianças e divisão do trabalho entre homens e mulheres". Sociologia, Problemas e Práticas, 28: 9-65.

VASCONCELOS, Pedro. (1998), "Práticas e discursos da conjugalidade e de sexualidade dos jovens portugueses", in Manuel Villaverde Cabral e José Machado Pais (orgs.), Jovens portugueses de hoje, Oeiras, Celta, pp. 215-305.

VELHO, Gilberto. (1998), Nobres \& anjos. Rio de Janeiro, Fundação Getulio Vargas.

. (2002), Subjectividade e sociedade: uma experiência de geração. Rio de Janeiro, Jorge Zahar Editor.

WALL, Karin \& GUERREIRO, Maria das Dores. (2005), "A divisão familiar do trabalho", in Karin Wall (coord.), Familias no Portugal contemporâneo, Lisboa, ICS (no prelo).

WEBER, Max. ([1922], 1971), Économie et société. Paris, Plon. 
COMO TORNAR-SE ADULTO: PROCESSOS DE TRANSIÇÃO NA MODERNIDADE AVANÇADA

Maria das Dores Guerreiro e

Pedro Abrantes

\section{Palavras-chave}

Transição para a vida adulta; Gerações; Trabalho; Família.

O presente artigo procura analisar as formas como os jovens se tornam adultos na modernidade avançada. As conclusões aqui apresentadas baseiam-se num projeto de investigação de âmbito europeu, o qual, além de uma pesquisa teórica e de fontes estatísticas, procedeu à realização de entrevistas de grupo e individuais a jovens de contextos sociais diferenciados e em situações de vida distintas, como forma de reconstituir condições e histórias de vida, práticas e representações, projetos e expectativas ante o futuro. A análise centra-se em quatro dimensões fundamentais: educação, trabalho, família e gênero, procurando a partir delas chegar a uma tipologia de modos de transição para a vida adulta.
HOW TO BECOME AN ADULT: TRANSICIONAL PROCESSES IN ADVANCED MODERNITY

\author{
Maria das Dores Guerreiro and \\ Pedro Abrantes
}

\section{Keywords}

Transition to adult life; Generations; Work and family.

This article seeks to analyze the ways in which the young people become adults in advanced modern societies. The conclusions presented here are based on a Europe-wide research project that not only involved theoretical and statistical research but also individual and group interviews with young people belonging to different social backgrounds and representing distinct life situations. The intention was to reconstruct practices and representations, life histories and conditions, and plans for and expectations of the future. In the search for an understanding of where young people of both sexes - with different social backgrounds and educational and quantificational levels - stand with regard to work and the family, typical modes of transition to adult life were identified.
COMMENT DEVENIR ADULTE: PROCÉDURES DE TRANSITION DANS LA MODERNITÉ AVANCÉE

Maria das Dores Guerreiro et Pedro Abrantes

\section{Mots-clés}

Transition vers la vie adulte; Générations; Travail et famille.

Cet article présente une analyse des différentes façons dont les jeunes deviennent adultes dans la modernité avancée. Les conclusions présentées sont tirées d'un projet de recherche à l'échelle européenne qui, en plus d'une recherche théorique et de sources statistiques, a procédé à la réalisation d'entretiens de groupe et d'entretiens individuels avec des jeunes de différents contextes sociaux et ayant des situations de vie distinctes, de manière à reconstituer les conditions et les histoires de vie, les pratiques et les représentations, les projets et les attentes face à l'avenir. Plusieurs modalités typiques de transition vers la vie adulte ont ainsi pu être identifiées, tout en essayant de comprendre la manière dont les jeunes des deux sexes, appartenant à des divers milieux sociaux et possédant des niveaux d'instruction et de qualification différents se situent par rapport au travail et à la famille. 